\title{
Review
}

\author{
Fei Guo*, Clemens M. Altaner and Michael C. Jarvis
}

\section{Thickness-dependent stiffness of wood: potential mechanisms and implications}

https://doi.org/10.1515/hf-2019-0311

Received December 20, 2019; accepted March 17, 2020; published online June 1, 2020

\begin{abstract}
When wood is split or cut along the grain, a reduction in tensile stiffness has been observed. The averaged mechanical properties of wood samples, veneers or splinters therefore change when their thickness is less than about $1 \mathrm{~mm}$. The loss of stiffness increases as the thickness approaches that of a single cell. The mechanism of the effect depends on whether the longitudinal fission plane is between or through the cells. Isolated single cells are a model for fission between cells. Each cell within bulk wood is prevented from twisting by attachment to its neighbours. Separation of adjacent cells lifts this restriction on twisting and facilitates elongation as the cellulose microfibrils reorientate towards the stretching direction. In contrast when the wood is cut or split along the centre of the cells, it appears that co-operative action by the $\mathrm{S}_{1}, \mathrm{~S}_{2}$ and $S_{3}$ cell-wall layers in resisting tensile stress may be disrupted. Since much of what is known about the nanoscale mechanism of wood deformation comes from experiments on thin samples, caution is needed in applying this knowledge to structural-sized timber. The loss of stiffness at longitudinal fracture faces may augment the remarkable capacity of wood to resist fracture by deflecting cracks into the axial plane. These observations also point to mechanisms for enhancing toughness that are unique to wood and have biomimetic potential for the design of composite materials.
\end{abstract}

Keywords: fracture; Poisson ratio; shear; single cells; tensile modulus.

*Corresponding author: Fei Guo, College of Material Engineering, Fujian Agriculture and Forestry University, Fuzhou, 350108, China; and New Zealand School of Forestry, University of Canterbury, Private Bag 4800, Christchurch, 8140, New Zealand, E-mail: guofei1129@hotmail.com

Clemens M. Altaner: New Zealand School of Forestry, University of Canterbury, Private Bag 4800, Christchurch, 8140, New Zealand Michael C. Jarvis: School of Chemistry, Glasgow University, Glasgow, G12 8QQ, Scotland, UK

\section{Introduction}

Trees can be taller than any other living structures on Earth, and are subjected to great forces by wind loading and their own weight (Koch et al. 2004). Nevertheless wood is not usually classed with strong biological materials like spider silk and bivalve byssus, which derive their exceptional fracture resistance from energy-absorbing flexibility (Bradley 2018; Liu et al. 2019). Wood is not flexible. Its stiffness varies from moderate to high depending on its position and structural function in the tree (Lachenbruch et al. 2011). Wood with cellulose microfibrils well-oriented along the cell axis has stiffness-toweight and strength-to-weight ratios greater than other biological materials and comparable with steel (Ashby et al. 1995).

Within a trunk the longitudinal modulus can vary by an order of magnitude between flexible juvenile wood at the base, laid down when the tree was a sapling bending freely, to very stiff mature wood in the outermost annual rings (Lachenbruch et al. 2011). The stiff mature wood is well placed to protect the trunk from buckling failure when subjected to compressive load under the weight of the fully-grown crown (Gardiner et al. 2016). The variation in stiffness within a tree is controlled mainly by the microfibril angle (MFA), the helical angle at which the cellulose microfibrils are wound round each wood cell in the dominant $\mathrm{S}_{2}$ layer of the wood cell wall (Reiterer et al. 1999). MFAs range from $5-10^{\circ}$ in stiff mature wood up to $45^{\circ}$ in flexible juvenile wood (Barnett and Bonham 2004).

In materials like glass fibre, thin dimensions impart freedom from flaws and therefore resistance to fracture (Griffith 1921). Similarly at length scales larger than millimetres, cutting wood into thin, knot-free laminations and gluing these together can yield laminated beams that are stronger than the original wood, in which fracture begins at knots (Blank et al. 2017). However, there is evidence that at smaller length scales, thin dimensions can degrade mechanical performance. Despite experimental difficulties in measuring tensile stiffness (Burgert and Keplinger 2013), a loss of stiffness has repeatedly been observed (Eder et al. 2013) when the lateral dimensions of a wood specimen 
approach the width of its constituent cells, approximately $30 \mu \mathrm{m}$.

This 'thin sample effect' implies that deformation mechanisms are facilitated, or that additional mechanisms come into play in thin wood samples under tension. Much of what is assumed about the molecular-scale deformation of structural timber is extrapolated from experiments on thin samples or single cells. Uncertainty therefore arises from this extrapolation, which has been hard to avoid because the relevant spectroscopic and scattering techniques (Eder et al. 2013) are mostly based on radiation that does not pass through more than $1 \mathrm{~mm}$ of wood. Exceptions are near-infrared spectroscopy (Guo and Altaner 2018), neutron scattering and synchrotron X-ray scattering experiments on wood deformed in bending mode (Alméras et al. 2017; Montero et al. 2012). Consequently these techniques are valuable for understanding nanoscale deformation mechanisms in wood with larger dimensions and identifying where we may have been misled by experiments on thin samples.

This review discusses a) some possible mechanisms for the observed loss in stiffness in thin sections and single cells of wood, and $b$ ) the implications for fracture processes in solid wood. Most of the published evidence concerns softwoods. Hardwoods and woody graminaceous plants like bamboo have cell walls of rather different polymer composition and architecture (Keplinger et al. 2014) and it needs to be confirmed whether the following considerations are applicable to hardwood and bamboo too.

\section{Observations of reduced stiffness in thin wood samples}

When softwoods are split or cut along the grain, the cells can either separate along the line of the middle lamella or split by rupture of the cell walls (Figure 1). On separating softwood material into single cells, even with great care to minimise damage, the tensile modulus is reduced (Keckes et al. 2003). Eder et al. (2013) collected data from a number of studies to show that single cells with low MFA had smaller tensile modulus than solid wood, while at high MFAs there was little difference. If an isolated wood cell is free to twist under tensile load, the tensile modulus is reduced further (Keckes et al. 2003). When a single cell is anchored at the ends for tensile testing it cannot twist overall, but local twisting remains possible at compliant domains along the cell's length (Eder et al. 2009; Keckes et al. 2003). Twisting is of course prevented when the cells adhere together in solid wood.

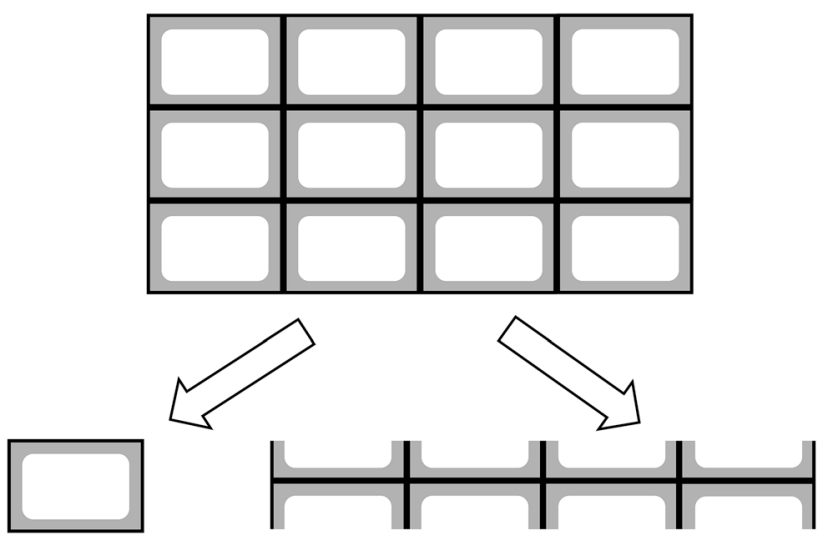

Figure 1: Cross-sections of wood separated in different ways: (left) single cell separated along the middle lamella; (right) thin sheet excised by cutting the cells lengthwise. Grey: secondary cell wall: black: compounds middle lamella; white: cell lumen.

It has been less widely recognised that splitting wood cells also reduces their stiffness, but Gierlinger (2018) showed that thin sheets of split cells (Figure 1), such as longitudinally microtomed sections, retain even less tensile stiffness than separated cells (Burgert and Jungnikl 2004; Navi et al. 1995; Reiterer et al. 1999; Yu et al. 2009). Mature spruce earlywood samples with relatively low MFA prepared in this way for FTIR spectroscopy, with a nominal section thickness of about $20 \mu \mathrm{m}$ comprising one doublewall sheet, had a tensile modulus of approximately $2 \mathrm{GPa}$ when dry or $1 \mathrm{GPa}$ when wet (Altaner et al. 2014; Salmén and Bergström 2009), much lower than the tensile modulus that would be expected for earlywood of macroscopic samples of the same species with the same MFA (Eder et al. 2009; USDA 2010). The difference in tensile modulus between the dry and wet states was also greater than in macroscopic wood samples. Smaller and more variable reductions in tensile modulus have been recorded for sections $200-500 \mu \mathrm{m}$ in thickness used for X-ray scattering experiments (Müller et al. 2011; Peura et al. 2007; Reiterer et al.1999). Biblis (1970) observed a positive relationship of tensile modulus to sample thickness over the $70-300 \mu \mathrm{m}$ range. Wang et al. (2017) found that dry $500 \mu \mathrm{m}$ thick microtomed sections had approximately the tensile moduli that would be expected for bulk pine samples of similar MFA, but effects on stiffness have been observed in veneers up to a thickness of about $1 \mathrm{~mm}$ (Buchelt and Pfriem 2011).

\section{Potential mechanisms}

We will first describe the stretching mechanisms proposed for thin samples including separated cells. In particular we 
will explore the evidence on how interfibrillar shear is facilitated. We will then return to the question of how wood in larger dimensions may differ.

The mechanism of tensile deformation depends on whether the MFA is high or low. Studies on hydrated single cells with high MFA have shown that elongation comes from rotation of the microfibrils towards the line of stress, is partially irreversible when the stress exceeds the yield point corresponding to a prominent break in the slope of the load-deformation curve, and is time-dependent (viscoelastic) (Keckes et al. 2003). Assuming that the microfibril and macrofibril spacings remain constant and the cell is prevented from twisting, microfibril rotation needs to be accompanied by shear so that the oppositehanded twisting tendencies of rotation and shear cancel (Keckes et al. 2003; Schniewind, 1972). Being observable in single cells, shear must take place within the cell wall and not between cells (Keckes et al. 2003). After irreversible shear deformation, the displaced microfibrils are mechanically effective in their new configuration. Irreversible elongation then absorbs energy without loss of strength (Altaner and Jarvis 2008; Keckes et al. 2003). Functionally, the deformation mechanism of wood resembles the different mechanisms that provide fracture energy in strong, but less stiff, protein-based materials like spider silk (Koebley et al. 2017).

In contrast, when the MFA is initially low there is not much room for cellulose fibrils to rotate (Peura et al. 2007; Reiterer et al. 2001; Wang et al. 2017) and the rotation contributes little increment in length. The relative elongation is $\delta \varepsilon=\delta \mathrm{L} / \mathrm{L}_{0}=\cos \mu-\cos \mu_{0}$, where $\mathrm{L}$ is the length, $\mu$ is the MFA and the index ${ }_{0}$ denotes the starting position. The derivative is $\delta \varepsilon / \mathrm{d} \mu=-\sin \mu$. Thus, the effect of, e. g. $1^{\circ}$ rotation becomes vanishingly small as $\mu_{0}$ approaches zero. So does the leverage transforming axial force into rotational force. These geometric considerations also apply to local deviations of microfibril orientation within the cell wall, such as waves and kinks.

Thin samples with low MFA do not show a distinct yield point in their load-deformation curves (e. g. Salmén and Bergström 2009). There is surprisingly little direct information on the extent to which their tensile deformation is irreversible.

The principal mechanism of elongation at low MFAs is the elastic stretching of the cellulose chains themselves (Altaner et al. 2014). However, if this were the only mechanism the projected strain on cellulose (crystallographic strain) would exactly match the macroscopic strain. It does not, especially when the wood is hydrated (Alméras et al. 2017). In thin wood samples with split cells at the surface, reduced macroscopic stiffness is associated with reduced stretching of the cellulose microfibrils as assessed by diffraction (Nakai et al. 2005; Peura et al. 2007). At a given macroscopic elongation, bandshifts in vibrational spectroscopy, a relative measure of the molecular stretching of cellulose chains, are time-dependent (Altaner et al. 2014) and reduced by hydration (Alméras et al. 2017).

The simplest interpretation of these observations is that the cellulose fibrils are not infinitely long (Abraham and Elbaum 2013; Reza et al. 2014) and that there is axial shear between them, making up the discrepancy between macroscopic and projected crystallographic strain. Cellulose strain returns to zero on unloading even when macroscopic strain does not, implying that axial shear is at least partially irreversible (Gierlinger 2018; Nakai et al. 2006; Peura et al. 2007).

Shear, in a plane parallel to the fibril orientation, is thus a key feature of the stretching of thin wood samples whether they have high or low MFA. At high MFA its presence is inferred from measurements of fibril rotation unaccompanied by net twisting of the wood cell (Reiterer et al. 2001). At low MFA its presence is inferred from the discrepancy between macroscopic and projected cellulose crystallographic strain. It may be asked whether, at the molecular scale, the mechanism of shear is the same at high and low MFA. In both situations shear is timedependent, partly irreversible and facilitated by moisture (Alméras et al. 2017; Keckes et al. 2003; Reiterer et al. 2001; Salmén and Bergström 2009; Wang et al. 2017). Differences include the lack of any apparent yield threshold in the load-deformation curve at low MFA (Kamiyama et al. 2005; Salmén and Bergström 2009). It is possible that at low MFA irreversibility only occurs above a threshold stress, but this is not clear from the data available (Nakai et al. 2006; Peura et al. 2007). It seems reasonable that there should be at least some common features between the molecular mechanisms of shear at high and low MFA, but it does not follow that the detailed mechanism and molecular-scale location are identical. Creep, which can happen at low stress level (USDA 2010), is likely accompanied by molecular shear but again the mechanistic details and location are unclear.

\section{Molecular-level shear}

The original formulation of the molecular shear mechanism proposed by Keckes et al. (2003) was based on models for the molecular structure of the wood cell wall that have since been superseded. It was assumed that single microfibrils were embedded in a hemicellulose-lignin matrix within which shear took place (Jin et al. 2015), resisted by 
polymer entanglement (Keckes et al. 2003) or by slanting hemicellulose bridges adherent to the microfibril surfaces (Altaner and Jarvis 2008).

It is now evident that in softwoods the $\sim 3 \mathrm{~nm}$ thick cellulose microfibrils are irregularly aggregated into larger units or macrofibrils, typically 10-20 nm thick (Donaldson 2007). A key question is therefore whether shear occurs between macrofibrils, or between microfibrils within each macrofibril. The visibility of macrofibrils at fracture faces (Zimmermann et al. 2007) suggests that shear takes place between macrofibrils at the fracture stress, although these observations do not rule out shear within macrofibrils as well, or at lower stresses. The matrix-filled spaces between hydrated macrofibrils are several nanometres wide (Cheng et al. 2014; Plaza et al. 2016), much wider than the spaces between microfibrils, and of the same order as the persistence length of hemicelluloses (Altaner and Jarvis 2008). Thus random coiling and entanglement involving molecular confinement (Keten and Buehler 2008) or molecular frustration (Silveira et al. 2013) might be possible for the matrix polymers. However, these polymers all have some degree of orientation (Simonović et al. 2011), which would make polymer entanglement less plausible than some form of axial sliding mechanism.

Until now our understanding of softwood structure has been insufficient to allow sliding mechanisms between microfibrils or between macrofibrils to be elaborated. However, the recent ${ }^{13} \mathrm{C}$ spin-diffusion NMR experiments of Terrett et al. (2019) have revealed interfibrillar structures within the macrofibrils. Xylan segments with alternating substituent pattern are hydrogen-bonded edge-on to cellulose microfibrils. Galactoglucomannan and lignin chains also interact with microfibril surfaces, in ways that are less clear (Terrett et al. 2019). Any or all of these three noncellulosic polymers would be suitably located to bridge non-covalently between microfibrils. There are also direct, hydrogen-bonded cellulose-cellulose contacts, which can be partially separated by hydration (Fernandes et al. 2011). In principle, shear within macrofibrils is possible at any of these non-covalent interfaces.

The ${ }^{13} \mathrm{C}$ spin-diffusion NMR experiments of Terrett et al. (2019) provide information on the relative location of polymer chains up to about $1 \mathrm{~nm}$ apart, and are therefore less suitable for discerning structures on the $>10 \mathrm{~nm}$ scale of the macrofibrils. However, the spectral assignments of Terrett et al. (2019) allow new information to be extracted from earlier ${ }^{1} \mathrm{H}$ spin-diffusion experiments (Altaner et al. 2008) which are more appropriate for longer length scales. In particular, a hemicellulose with ${ }^{13} \mathrm{C} C-1$ signal at $101 \mathrm{ppm}$ (Altaner et al. 2006) can now be identified as galactoglucomannan (Terrett et al. 2019). The main components of domains at a distance of several nanometre from cellulose can thus be identified as acetylated galactoglucomannan and lignin (Altaner et al. 2006), implying that these two polymers are present in the matrix between macrofibrils and could participate in shear at that location. Alternatively, single slanting microfibrils might bridge from one macrofibril to the next (Jarvis 2018), retained by direct cellulose-cellulose adhesion (Oehme et al. 2015). Numerical simulations based on earlier models of wood structure have yielded predictions of softwood deformation in some agreement with observation (Eitelberger et al. 2012; Jin et al. 2015), but that does not prove that the structures assumed were correct, and more detailed structural information will be needed before we can assemble a realistic picture of how the nanoscale structure deforms under tensile load.

A further question is the mechanism by which extension dependent on interfibrillar shear is facilitated by proximity to the wood surface. Yu et al. (2009) attempted to describe the surface effects in terms of shear between cellwall layers. In the case of surfaces where high-MFA cells have separated, reduced stiffness was attributed to removal of the shear resistance along the middle lamella that, in intact wood, balances the twisting tendencies of adjacent cells. The analysis of Yu et al. (2009) then approximates to the more quantitative single-cell analyses of Keckes et al. (2003), Schniewind (1972) and especially Fratzl et al. (2004) describing plastic deformation of highMFA samples.

In split cells with low MFA the nature of the surface effect must be different and is unclear, but the inclusion of shear between the $S_{1}, S_{2}$ and $S_{3}$ layers of each cell wall (Schniewind 1972; Yu et al. 2009) suggests possibilities equally unique to wood and rich in biomimetic potential. In wood with high strength and stiffness the well-oriented cellulose $\left(<10^{\circ}\right.$ to the cell axis) occupies the thick, middle $\left(\mathrm{S}_{2}\right)$ layer of the secondary cell wall (Figure 2), the layer that is considered to dominate the tensile performance of the wood (Barnett and Bonham 2004). Lying nearly parallel to the splitting direction, cellulose microfibrils in the $S_{2}$ layer would be damaged least if the cell is split longitudinally, with little reduction in their length, and no great loss of stiffness would therefore be expected. Most of the rupture of microfibrils would be in the thin, outer $\left(\mathrm{S}_{1}\right)$ and inner $\left(\mathrm{S}_{3}\right)$ wall layers where the winding angle is higher (Barnett and Bonham 2004; Reza et al. 2017), probably too high for these microfibrils to contribute much stiffness directly. The observation of greatly reduced tensile stiffness of the cell wall as a whole, accompanying damage to cellulose microfibrils in the $S_{1}$ and $S_{3}$ layers, suggests that when intact these thinner layers may have an indirect role in the tensile 
performance of wood (Plaza et al. 2016), perhaps through restraining the circumferential contraction of the $S_{2}$ layer that accompanies elongation as described by the Poisson ratio of approximately 0.5 (Davies et al. 2016). Non-specific damage to cell walls during sample preparation when cells are split or separated may also compromise wood stiffness.

An additional - or alternative - observation is that the tensile stiffness is not constant along the length of any one cell but differs in localised domains (Keckes et al. 2003; Navi et al. 1995). Such domains are found in the neighbourhood of pits where the microfibril orientation deviates from axial to sweep around bordered pits (Lichtenegger et al. 2003), and the local tensile modulus is therefore reduced. In intact wood these extensible regions are supported by the attached neighbouring cells, but for single isolated cells there is no such support (Sedighi-Gilani and Navi 2007), while at a surface where the cells have been separated or cut, the amount of support is reduced (Navi et al. 1995). The elongation of the unsupported cell wall may then be concentrated in limited, high-MFA domains along the cell length (Navi et al. 1995), which stretch successively on reaching a yield threshold like cells of uniformly high MFA (Fratzl et al. 2004).

\section{Tensile elongation of thick samples}

The experiments described above on single cells and thin microtome sections would not have been possible in thick wood samples, but a small number of publications describe experimental approaches that avoid this limitation. The influence of a nearby sample surface was evident in the diffraction-based bending experiments of Alméras, et al. (2017) and Montero et al. (2012): despite considerable

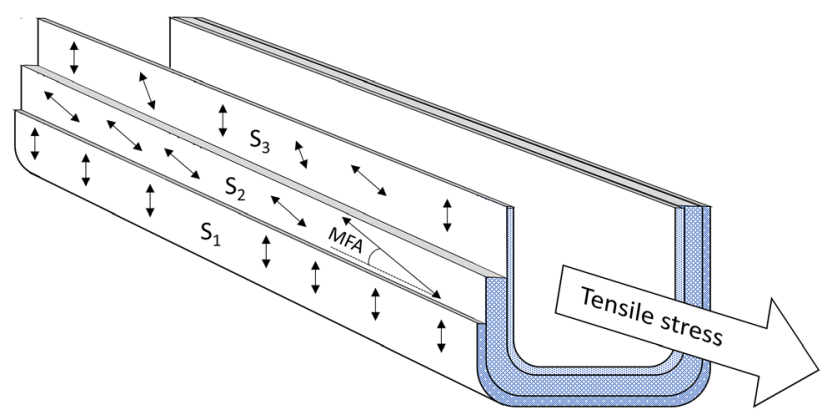

Figure 2: A single wood cell split to show the thin $S_{1}$, thick $S_{2}$ and thin $S_{3}$ layers and the microfibril orientations (double headed arrows) within each layer. The microfibril orientation in the $S_{2}$ layer is taken as the microfibril angle (MFA). variability between samples it appeared that throughout the thickness of the sample the crystallographic strain was less than the macroscopic strain, diverging particularly within a few tens of micrometres from the tension and compression surfaces (Alméras et al. 2017).

Thin wood sections are normally associated with pronounced tensile stress relaxation, but lower levels of viscoelastic behaviour can also be observed in macroscopic samples (Taniguchi and Ando 2010). Guo and Altaner $(2018,2019)$ used transmission NIR on pine and eucalyptus samples up to $1 \mathrm{~mm}$ thick, sufficient to reduce the stress relaxation to only $2-4 \%$ during the measurement. Bandshifts in the first overtones of the $\mathrm{O}-\mathrm{H}$ stretching modes of cellulose, indicating molecular strain on microfibrils, were reversible at low macroscopic strain levels $(<0.25 \%)$ and linear with tensile strain (Guo and Altaner 2018). This implies that shear deformation in low MFA wood becomes irreversible only when the applied stress exceeds a threshold. Taniguchi and Ando (2010) observed that the lateral contraction of macroscopic softwood samples under tension differed from their longitudinal elongation in time dependence, stress relaxation and reversibility, so that the macroscopic Poisson ratio was time-dependent. The macroscopic Poisson ratio was also dependent on moisture content (Mizutani and Ando 2015). These observations would be consistent with interfibrillar shear and interactions between cell-wall layers as suggested above for thin samples, although other explanations are possible. At constant relative humidity the wood cell walls absorbed water under tensile stress (Guo and Altaner 2019), illustrating the coupling between mechanical and hygroscopic properties of wood (Navi and StanzlTschegg 2009).

The phenomenon of mechano-sorptive creep, when deformation occurs under load during fluctuations in moisture content, is observed in timber of structural dimensions (Martensson 1994). Wood at constant high moisture content also exhibited enhanced creep behaviour (Hering and Niemz 2012), which is parallelled in living trees (Ray and Bret-Harte 2019). Like the tensile deformation of thin wood samples creep is a molecular phenomenon, time-dependent and facilitated by moisture (Martensson 1994). A decreased elastic modulus and increased irreversibility were also found in moist bulk wood at high stresses, approaching the fracture stress (Smith et al. 2003). It remains to be established whether these parallels with thin samples imply shared mechanistic features at the molecular level.

Summarising what is known about mechanisms, the substantial fractions of the tensile deformation of single cells and thin wood foils that are irreversible and 
dependent on time and moisture require shear between microfibrils and/or macrofibrils. Interfibrillar shear may also occur in wood of structural dimensions at constant high moisture content, but if so it would appear to be either smaller in magnitude than in thin samples, or largely reversible, contributing to the restoring force under tension. Extrapolation of mechanistic concepts from thin samples to bulk wood requires caution until the magnitude of the shear contributions to elongation, their dependence on sample thickness and the origins of threshold stresses are much better understood. We can, however, say that features of the structure of bulk wood, at the scale of cell walls and larger, make a substantial and largely unexplored contribution to its stiffness, in ways that would inform materials science in general if they were better understood.

\section{Implications for fracture}

The above phenomena are relevant to fracture processes. The longitudinal tensile strength of wood owes much to crack-stopping mechanisms at various length scales (Conrad et al. 2003; Smith et al. 2003). At the scale of macrofibrils (tens of $\mathrm{nm}$ ), wood cells (tens of $\mu \mathrm{m}$ ) or annual rings $(\mathrm{mm})$ weak interfaces deflect transverse cracks into the longitudinal plane (Barthelat et al. 2016; Marthin and Gamstedt 2019), where they propagate mainly in shear (Smith et al. 2003). Wood therefore typically splinters, and most of the fracture surface area and associated fracture energy (Gamstedt et al. 2013; Wang et al. 2019) lie along the grain (Figure 3). Whether wood splits naturally between the cells or along the cell walls depends on its density. The thick-walled cells of dense wood tend to separate, whereas thin cell walls split (Ashby et al. 1985; Lanvermann et al. 2014).

The reduced stiffness of split or separated wood cells has consequences for fracture that are largely unexplored and will be only briefly and tentatively outlined here. When a transverse tensile crack has been deflected along the grain (Bodner et al. 1997; Wang et al. 2019) its propagation is driven by longitudinal shear stress at the same time as the arrested transverse crack widens (Figure 4). Transmission of elastic energy longitudinally to the crack tip will then be reduced by the lower tensile stiffness at the longitudinal fracture surfaces. Longitudinal unloading of the cells or half-cells near the tip of the deflected crack will also make it more difficult for the crack to resume a transverse path (Bodner et al. 1997).

The crack-stopping mechanism suggested above is at the scale of wood cell diameters (tens of $\mu \mathrm{m}$ ). Energy-

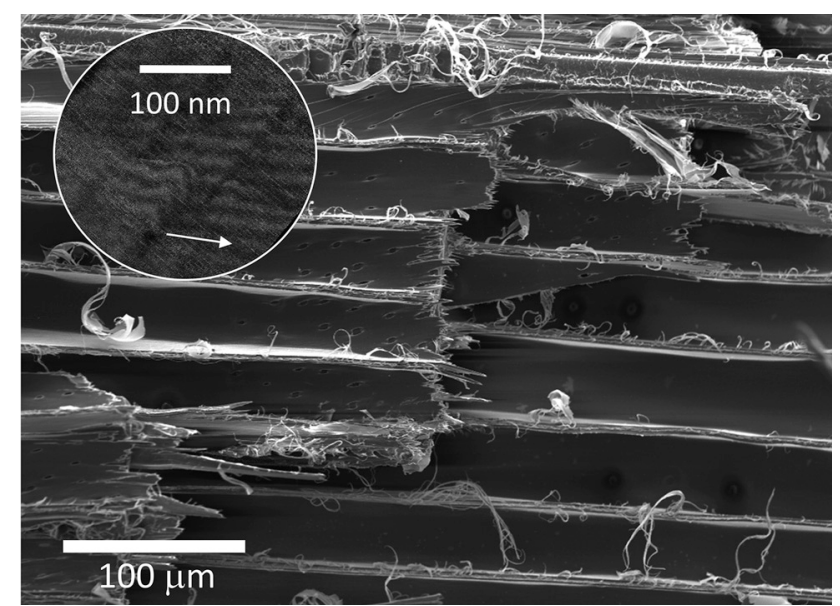

Figure 3: SEM image of the fracture surface of a Sitka spruce (Picea sitchensis) earlywood sample broken under tensile stress along the grain from left to right, showing (centre of image) a transverse crack across four cells associated with diagonal splits in pit fields with relatively high microfibril angle. The transverse crack is deflected into the longitudinal plane to the right and left, where the shear fracture in the longitudinal cell walls is ragged, with curled fibres consistent with the residues of bridging. The longitudinal fractures in this sample continued far beyond the right and left edges of the image and the ratio of the longitudinal to transverse fracture plane area was approximately 40-1. Inset: AFM image of the same sample at higher magnification showing a stepped fracture surface, with transverse cracks running across sheets of macrofibrils about $20 \mathrm{~nm}$ in thickness, and deflected into the longitudinal plane between these sheets. The arrow indicated the longitudinal direction of the macrofibrils.

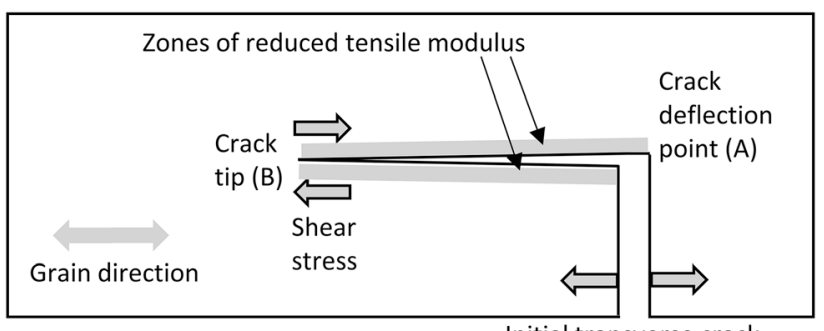

Initial transverse crack

Figure 4: Simplified diagram of a transverse tensile crack deflected into longitudinal shear. Transmission of the shear stress to the longitudinal crack tip (B) is predicted to be reduced if proximity to the longitudinal fracture surface reduces the local tensile modulus.

dissipation (toughening) characteristics are also predicted to occur at the scale of macrofibrils (tens of $\mathrm{nm}$ ) adjacent to fracture surfaces where shear between or within macrofibrils is facilitated as described above (Barthelat et al. 2016; Marthin and Gamstedt 2019). Images of fracture surfaces (e. g. Figure 3) are consistent with this prediction (Zimmermann et al. 2007). At the millimetre scale every 
annual ring of a coniferous tree contains both low- and high-density wood, in which longitudinal fracture is likely to be at intracellular and extracellular surfaces respectively (Ashby et al. 1985; Lanvermann et al. 2014). Ring boundaries are thus a further, mm-scale location where cracks may be arrested or deflected into a relatively harmless longitudinal direction (Lukacevic and Füssl 2016; Thuvander et al. 2000; Wang et al. 2019). An intriguing possibility is that ring boundaries might play a more important role in species such as Douglas Fir with a high ratio of latewood to earlywood density (USDA 2010), in comparison for example with redwoods in which the density is more homogeneous across annual rings.

The splintering of a tree trunk broken by the wind can be seen as a survival mechanism, protecting the wood that remains unbroken and reducing the likelihood of complete failure (Müller et al. 2018). If the break is not complete, bent splinters may continue to carry sap and keep the crown of the tree alive.

Acknowledgments: We thank Profs M. Cusack and H. Yin (Glasgow University), respectively for the SEM and AFM images shown in Figure 3.

Author contributions: All the authors have accepted responsibility for the entire content of this submitted manuscript and approved submission.

Research funding: None declared.

Employment or leadership: None declared.

Honorarium: None declared.

Conflict of interest statement: The authors declare no conflicts of interest regarding this article.

\section{References}

Abraham, Y. and Elbaum, R. (2013). Quantification of microfibril angle in secondary cell walls at subcellular resolution by means of polarized light microscopy. New. Phytol. 197: 1012-1019, https://doi.org/10.1111/nph.12070.

Alméras, T., Gronvold, A., van der Lee, A., Clair, B., and Montero, C. (2017). Contribution of cellulose to the moisture-dependent elastic behaviour of wood. Compos. Sci. Technol. 138: 151-160, https://doi.org/10.1016/j.compscitech.2016.11.025.

Altaner, C., Apperley, D.C., and Jarvis, M.C. (2006). Spatial relationships between polymers in Sitka spruce: proton spindiffusion studies. Holzforschung 60: 665-673, https://doi.org/ 10.1515/hf.2006.112.

Altaner, C.M., and Jarvis, M.C. (2008). Modelling polymer interactions of the 'molecular Velcro' type in wood under mechanical stress. J. Theor. Biol. 253: 434-445, https://doi.org/10.1016/j.jtbi. 2008.03.010.

Altaner, C.M., Thomas, L.H., Fernandes, A.N., and Jarvis, M.C. (2014). How cellulose stretches: synergism between covalent and hydrogen bonding. Biomacromolecules 15: 791-798, https:// doi.org/10.1021/bm401616n.

Ashby, M.F., Easterling, K.E., Harrysson, R., and Maiti, S.K. (1985). The fracture and toughness of woods. Proc. R. Soc. London, Ser. A 398: 261-280, https://doi.org/10.1098/rspa.1985.0034.

Ashby, M.F., Gibson, L.J., Wegst, U., and Olive, R. (1995). The mechanical properties of natural materials. 1. Material property charts. Proc. Roy. Soc. Lond. Math. Phys. Sci. 450: 123-140, https://doi.org/10.1098/rspa.1995.0075.

Barnett, J.R. and Bonham, V.A. (2004). Cellulose microfibril angle in the cell wall of wood fibres. Biol. Rev. Camb. Phil. Soc. 79: 461-472, https://doi.org/10.1017/s1464793103006377.

Barthelat, F., Yin, Z., and Buehler, M. J. (2016). Structure and mechanics of interfaces in biological materials. Nat. Rev. Mater. 1: 16007, https://doi.org/10.1038/natrevmats.2016.7.

Biblis, E.J. (1970). Effect of thickness of microtome sections on their tensile properties. Wood Fiber Sci. 2: 19-30.

Blank, L., Fink, G., Jockwe, R., Frangi, A., (2017). Quasi-brittle fracture and size effect of glued laminated timber beams. Eur. J. Wood Wood Prod. 75, 667-681, https://doi.org/10.1007/s00107-0171156-0.

Bodner, J., Schlag, M.G., and Grull, G. (1997). Fracture initiation and progress in wood specimens stressed in tension .1. Clear wood specimens stressed parallel to the grain. Holzforschung 51: 479-484, https://doi.org/10.1515/hfsg.1997.51.5.479.

Bradley, D. (2018). Outstripping spider silk with cellulose. Mater. Today 21: 695-695, https://doi.org/10.1016/j.mattod.2018.07.004.

Buchelt, B. and Pfriem, A. (2011). Influence of wood specimen thickness on its mechanical properties by tensile testing: solid wood versus veneer. Holzforschung 65: 249-252, https://doi. org/10.1515/hf.2011.032.

Burgert, I. and Jungnikl, K. (2004). Adaptive growth of gymnosperm branches-ultrastructural and micromechanical examinations. J. Plant Growth Regul. 23: 76-82, https://doi.org/10.1007/ s00344-004-0042-2.

Burgert, I. and Keplinger, T. (2013). Plant micro- and nanomechanics: experimental techniques for plant cell-wall analysis. J. Exp. Bot. 64: 4635-4649, https://doi.org/10.1093/jxb/ert255.

Cheng, W., Wu, Z., Zhou, M., Xing, X., Mo, G., and Wu, Z. (2014). Impact of heating on the nanostructure of Red pine studied by small angle X-ray scattering. J. Anal. Appl. Pyrol. 108: 222-227, https://doi.org/10.1016/j.jaap.2014.04.013.

Conrad, M.P.C., Smith, G.D., and Fernlund, G. (2003). Fracture of solid wood: A review of structure and properties at different length scales. Wood Fiber Sci. 35: 570-584.

Davies, N.T., Altaner, C.M., and Apiolaza, L.A. (2016). Elastic constants of green Pinus radiata wood. N. Z. J. For. Sci. 46: 6, https://doi. org/10.1186/s40490-016-0075-x.

Donaldson, L. (2007). Cellulose microfibril aggregates and their size variation with cell wall type. Wood Sci. Technol. 41: 443-460, https://doi.org/10.1007/s00226-006-0121-6.

Eder, M., Jungnikl, K., and Burgert, I. (2009). A close-up view of wood structure and properties across a growth ring of Norway spruce (Picea abies L Karst.). Trees (Heidelberg, Ger.) 23: 79-84, https://doi.org/10.1007/s00468-008-0256-1.

Eder, M., Arnould, O., Dunlop, J.W.C., Hornatowska, J., and Salmén, L. (2013). Experimental micromechanical characterisation of wood cell walls. Wood Sci. Technol. 47: 163-182, https://doi.org/10. 1007/s00226-012-0515-6. 
Eitelberger, J., Bader, T.K., de Borst, K., and Jäger, A. (2012). Multiscale prediction of viscoelastic properties of softwood under constant climatic conditions. Comput. Mater. Sci. 55: 303-312, https:// doi.org/10.1016/j.commatsci.2011.11.033.

Fernandes, A.N., Thomas, L.H., Altaner, C.M., Callow, P., Forsyth, V.T., Apperley, D.C., Kennedy, C.J., and Jarvis, M.C. (2011). Nanostructure of cellulose microfibrils in spruce wood. Proc. Natl. Acad. Sci. U.S.A. 108: E1195-E1203, https://doi.org/10. 1073/pnas.1108942108.

Fratzl, P., Burgert, I., and Keckes, J. (2004). Mechanical model for the deformation of the wood cell wall. Z. Metallkd. 95: 579-584, https://doi.org/10.3139/146.017991.

Gamstedt, E.K., Bader, T.K., and de Borst, K. (2013). Mixed numericalexperimental methods in wood micromechanics. Wood Sci. Technol. 47: 183-202, https://doi.org/10.1007/s00226-0120519-2.

Gardiner, B., Berry, P., and Moulia, B. (2016). Review: Wind impacts on plant growth, mechanics and damage. Plant Sci. (Shannon, Irel.) 245: 94-118, https://doi.org/10.1016/j.plantsci.2016.01.006.

Gierlinger, N. (2018). New insights into plant cell walls by vibrational microspectroscopy. Appl. Spectrosc. Rev. 53: 517-551, https:// doi.org/10.1080/05704928.2017.1363052.

Griffith, A.A. (1921). The phenomena of rupture and flow in solids. Philos. Trans. R. Soc. London, Ser. A 221: 163-198, https://doi. org/10.1098/rsta.1921.0006.

Guo, F. and Altaner, C.M. (2018). Molecular deformation of wood and cellulose studied by near infrared spectroscopy. Carbohydr. Polym. 197: 1-8, https://doi.org/10.1016/j.carbpol.2018.05.064.

Guo, F. and Altaner, C.M. (2019). Effects of mechanical stretching, desorption and isotope exchange on deuterated eucalypt wood studied by near infrared spectroscopy. Spectrochim. Acta, Part A 211: 254-259, https://doi.org/10.1016/j.saa. 2018.12.012.

Hering, S. and Niemz, P. (2012). Moisture-dependent, viscoelastic creep of European beech wood in longitudinal direction. Eur. J. Wood Wood Prod. 70: 667-670, https://doi.org/10.1007/ s00107-012-0600-4.

Jarvis, M.C. (2018). Structure of native cellulose microfibrils, the starting point for nanocellulose manufacture. Phil. Trans. Math. Phys. Eng. Sci. 376: 20170045, http://dx.doi.org/10.1098/rsta. 2017.0045

Jin, K., Qin, Z., and Buehler, M.J. (2015). Molecular deformation mechanisms of the wood cell wall material. J. Mech. Behav. Biomed. Mater. 42: 198-206, https://doi.org/10.1016/j.jmbbm. 2014.11.010.

Kamiyama, T., Suzuki, H., and Sugiyama, J. (2005). Studies of the structural change during deformation in Cryptomeria japonica by time-resolved synchrotron small-angle X-ray scattering. J. Struct. Biol. 151:1-11, https://doi.org/10.1016/j.jsb.2005.04.007.

Keckes, J., Burgert, I., Frühmann, K., Müller, M., Kölln, K., Hamilton, M., Burghammer. M., Roth, S.V., Stanzl-Tschegg, S., and Fratzl, P. (2003). Cell-wall recovery after irreversible deformation of wood. Nat. Mater. 2: 810-814, https://doi.org/10.1038/ nmat1019.

Keplinger, T., Konnerth, J., Aguié-Béghin, V., Rüggeberg, M., Gierlinger, N., and Burgert, I. (2014). A zoom into the nanoscale texture of secondary cell walls. Plant Methods 10: 7, https://doi. org/10.1186/1746-4811-10-1.

Keten, S. and Buehler, M.J. (2008). Geometric confinement governs the rupture strength of $\mathrm{H}$-bond assemblies at a critical length scale. Nano Lett. 8: 743-748, https://doi.org/10.1021/ nl0731670.

Koch, G.W., Sillett, S.C., Jennings, G.M., and Davis, S.D. (2004). The limits to tree height. Nature 428: 851-854, https://doi.org/10. 1038/nature02417.

Koebley, S.R., Vollrath, F., and Schniepp, H.C. (2017). Toughnessenhancing metastructure in the recluse spider's looped ribbon silk. Mater. Horiz. 4: 377-382, https://doi.org/10.1039/ c6mh00473c.

Lachenbruch, B., Moore, J.R., and Evans, R. (2011). Radial variation in wood structure and function in woody plants, and hypotheses for its occurrence. In: Meinzer, F.C., Dawson, T., and Lachenbruch, B. (Eds), Size- and age-related changes in tree structure and function, Vol. 4. Springer, Netherlands, Dordrecht, pp. 121-164.

Lanvermann, C., Hass, P., Wittel, F.K., and Niemz, P. (2014). Mechanical properties of Norway Spruce: intra-ring variation and generic behavior of earlywood and latewood until failure. Bioresources 9: 105-119, https://doi.org/10.15376/biores.9.1. 105-119.

Lichtenegger, H.C., Müller, M., Wimmer, R., and Fratzl, P. (2003). Microfibril angles inside and outside crossfields of Norway spruce tracheids. Holzforschung 57: 13-20, https://doi.org/10. 1515/hf.2003.003.

Liu, Z., Zhang, Y., Zhang, M., Tan, G., Zhu, Y., Zhang, Z., and Ritchie, R.O. (2019). Adaptive structural reorientation: Developing extraordinary mechanical properties by constrained flexibility in natural materials. Acta Biomater. 86: 96-108, https://doi.org/ 10.1016/j.actbio.2019.01.010

Lukacevic, M. and Füssl, J. (2016). Application of a multisurface discrete crack model for clear wood taking into account the inherent microstructural characteristics of wood cells. Holzforschung 70 : 845-853, https://doi.org/10.1515/hf-2015-0162.

Mårtensson, A. (1994). Mechano-sorptive effects in wooden material. Wood Sci. Technol. 28: 437-449, https://doi.org/10.1007/ bf00225463.

Marthin, O. and Gamstedt, E.K. (2019). Damage shielding mechanisms in hierarchical composites in nature with potential for design of tougher structural materials. R. Soc. Open Sci. 6: 181733, https://doi.org/10.1098/rsos.181733.

Mizutani, M., and Ando, K. (2015). Influence of a wide range of moisture contents on the Poisson's ratio of wood. J. Wood Sci. 61: 81-85, https://doi.org/10.1007/s10086-014-1438-7.

Montero, C., Clair, B., Alméras, T., van der Lee, A., and Gril, J. (2012). Relationship between wood elastic strain under bending and cellulose crystal strain. Compos. Sci. Technol. 72: 175-181, https://doi.org/10.1016/j.compscitech.2011.10.014.

Müller, M., Krasnov, I., Ogurreck, M., Blankenburg, M., Pazera, T., and Seydel, T. (2011). Wood and silk: hierarchically structured siomaterials investigated in situ with X-ray and neutron scattering. Adv. Eng. Mater. 13: 767-772, https://doi.org/10. 1002/adem. 201000347.

Müller, U., Gindl-Altmutter, W., and Keckes, J. (2018). How softwood tree branches are attached to stems: hierarchical extension of Shigo's stem-branch model. Trees (Heidelberg, Ger.) 32: 1113-1121, https://doi.org/10.1007/s00468-018-1699-7.

Nakai, T., Yamamoto, H., and Nakao, T. (2005). The relationship between macroscopic strain and crystal lattice strain in wood under uniaxial stress in the fiber direction. J. Wood Sci. 51: 193-194, https://doi.org/10.1007/s10086-005-0697-8. 
Nakai, T., Yamamoto, H., Nakao, T., and Hamataki, M. (2006). Mechanical behavior of the crystal lattice of natural cellulose in wood under repeated uniaxial tension stress in the fiber direction. Wood Sci. Technol. 40: 683-695, https://doi.org/10. 1007/s00226-006-0095-4.

Navi, P., Rastogi, P.K., Gresse, V., and Tolou, A. (1995). Micromechanics of wood subjected to axial tension. Wood Sci. Technol. 29: 411-429, https://doi.org/10.1007/bf00194199.

Navi, P. and Stanzl-Tschegg, S. (2009). Micromechanics of creep and relaxation of wood. A review COST Action E35 2004-2008: Wood machining - micromechanics and fracture. Holzforschung 63: 186-195, https://doi.org/10.1515/hf.2009.013.

Oehme, D.P., Doblin, M.S., Wagner, J., Bacic, A., Downton, M.T., and Gidley, M.J. (2015). Gaining insight into cell wall cellulose macrofibril organisation by simulating microfibril adsorption. Cellulose 22: 3501-3520, https://doi.org/10.1007/s10570-0150778-9.

Peura, M., Kölln, K., Grotkopp, I., Saranpää, P., Müller, M., and Serimaa, R. (2007). The effect of axial strain on crystalline cellulose in Norway spruce. Wood Sci. Technol. 41: 565-583, https://doi.org/10.1007/s00226-007-0141-x.

Plaza, N.Z., Pingali, S.V., Qian, S., Heller, W.T., and Jakes, J.E. (2016). Informing the improvement of forest products durability using small angle neutron scattering. Cellulose 23: 1593-1607, https://doi.org/10.1007/s10570-016-0933-y.

Ray, P.M. and Bret-Harte, M.S. (2019). Elastic and irreversible bending of tree and shrub branches under cantilever loads. Front. Plant Sci. 10: 59, https://doi.org/10.3389/fpls.2019. 00059.

Reiterer, A., Lichtenegger, H., Fratzl, P., and Stanzl-Tschegg, S.E. (2001). Deformation and energy absorption of wood cell walls with different nanostructure under tensile loading. J. Mater. Sci. 36: 4681-4686, https://doi.org/10.1023/A: 1017906400924.

Reiterer, A., Lichtenegger, H., Tschegg, S., and Fratzl, P. (1999). Experimental evidence for a mechanical function of the cellulose microfibril angle in wood cell walls. Philos. Mag. A 79: 2173-2184, https://doi.org/10.1080/ 01418619908210415.

Reza, M., Bertinetto, C., Ruokolainen, J., and Vuorinen, T. (2017). Cellulose elementary fibrils assemble into helical bundles in $\mathrm{S}_{1}$ layer of spruce tracheid wall. Biomacromolecules 18: 374-378, https://doi.org/10.1021/acs.biomac.6b01396.

Reza, M., Ruokolainen, J, and Vuorinen, T. (2014). Out-of-plane orientation of cellulose elementary fibrils on spruce tracheid wall based on imaging with high-resolution transmission electron microscopy. Planta 240: 565-573, https://doi.org/10.1007/ s00425-014-2107-1.

Salmén, L. and Bergström, E. (2009). Cellulose structural arrangement in relation to spectral changes in tensile loading
FTIR. Cellulose 16: 975-982, https://doi.org/10.1007/s10570009-9331-z.

Schniewind, A. P. (1972). Elastic behavior of the wood fiber. In: Theory and design of wood and fiber composite materials, Eds. Jayne, B.A. Syracuse University Press. New York, USA, pp. 83-95.

Sedighi-Gilani, M., Navi, P. (2007). Experimental observations and micromechanical modeling of successive-damaging phenomenon in wood cells' tensile behavior. Wood Sci. Technol. 41: 69-85, https://doi.org/10.1007/s00226-006-0094-5.

Silveira, R.L., Stoyanov, S.R., Gusarov, S., Skaf, M.S., and Kovalenko, A. (2013). Plant biomass recalcitrance: effect of hemicellulose composition on nanoscale forces that control cell call strength. J. Am. Chem. Soc. 135: 19048-19051, https://doi.org/10.1021/ ja405634k.

Simonović, J., Stevanic, J., Djikanović, D., Salmén, L., and Radotić, K. (2011). Anisotropy of cell wall polymers in branches of hardwood and softwood: a polarized FTIR study. Cellulose 18: 1433-1440, https://doi.org/10.1007/s10570-011-9584-1.

Smith, I., Landis, E., and Gong, M. (2003). Fracture and fatigue in wood. Wiley, Chichester. ISBN 0-471-48708-2.

Taniguchi, Y. and Ando, K. (2010). Time dependence of Poisson's effect in wood I: the lateral strain behavior. J. Wood Sci. 56: 100-106, https://doi.org/10.1007/s10086-009-1070-0.

Terrett, O.M., Lyczakowski, J.J., Yu, L., luga, D., Franks, W.T., Brown, S.P., Dupree, R., and Dupree, P. (2019). Molecular architecture of softwood revealed by solid-state NMR. Nat. Commun. 10: 4978. (Terrett et al. 2019), https://doi.org/10.1038/s41467-019-12979-9.

Thuvander, F., Jernkvist, L.O., and Gunnars, J. (2000). Influence of repetitive stiffness variation on crack growth behaviour in wood. J. Mater. Sci. 35: 6259-6266, https://doi.org/10.1023/A: 1026766203501.

USDA (2010). Wood handbook - wood as an engineering material. General Technical Report FPL-GTR-190, Forest Products Laboratory, Madison, Wisconsin.

Wang, D., Lin, L.Y., Fu, F., and Fan, M.Z. (2019). The softwood fracture mechanisms at the scales of the growth ring and cell wall under bend loading. Wood Sci. Technol. 16: 1215-1230, https://doi. org/10.1007/s00226-019-01132-w.

Wang, H., Yu, Z., Zhang, X., Ren, D., and Yu, Y. (2017). The combined effects of initial microfibrillar angle and moisture contents on the tensile mechanical properties and angle alteration of wood foils during tension. Holzforschung 71: 491-497, https://doi.org/10. 1515/hf-2016-0138.

Yu, Y., Jiang, Z., and Tian, G. (2009). Size effect on longitudinal MOE of microtomed wood sections and relevant theoretical explanation. For. Stud. China 11: 243-248, https://doi.org/10.1007/s11632009-0040-3.

Zimmermann, T., Richter, K., Bordeanu, N., and Sell, J. (2007). Arrangement of cell-wall constituents in chemically treated Norway spruce tracheids. Wood Fiber Sci. 39: 221-231. 